\title{
Catalytic Asymmetric Coupling of 2-Naphthols by Chiral Tridentate Oxovanadium(IV) Complexes
}

\author{
Sang-Wen Hon, ${ }^{\dagger}$ Chun-Hsin Li, ${ }^{\dagger}$ Jen-Huang Kuo, ${ }^{\dagger}$ N. B. Barhate, ${ }^{\dagger}$ Yi-Hung Liu, ${ }^{\ddagger}$ \\ Yu Wang, ${ }^{\ddagger}$ and Chien-Tien Chen ${ }^{\star}, \dagger$
}

\begin{abstract}
Department of Chemistry, National Taiwan Normal University, and Instrumentation Center, College of Science, National Taiwan University, Taipei, Taiwan, R.O.C
\end{abstract}

chefv043@scc.ntnu.edu.tw

Received January 2, 2001

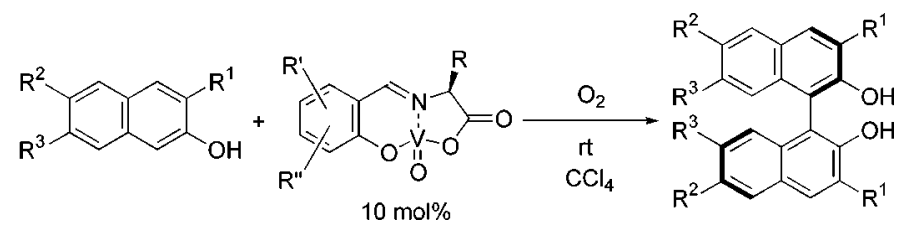

A series of chiral oxovanadium(IV) complexes derived from tridentate $\mathrm{N}-3,5$-substituted and $\mathrm{N}-3,4-\mathrm{benzo}$ - and $\mathrm{N}-5,6$-benzo-salicylidene- $\alpha-$ amino acids can serve as efficient catalysts for the enantioselective oxidative couplings of various 3-, 6-, and 7-substituted 2-naphthols under $\mathrm{O}_{2}$. The best scenario involves the use of a vanadyl complex arising from 2-hydroxy-1-naphthaldehyde and valine (or phenylalanine) in $\mathrm{CCl}_{4}$, leading to BINOLs in good yields (75-100\%) and with enantioselectivities of up to $68 \%$.

Optically active 1,1'-bi-2-naphthol (BINOL) and its derivatives have been extensively utilized as versatile prosthetic groups and chiral ligands in a myriad array of asymmetric transformations and catalyses when combined with suitable Lewis acids. ${ }^{1}$ In addition, their well-established conversions to the corresponding 2,2'-bis(diphenylphosphino)-1,1'-binaphyls (BINAP) further expand their synthetic utility in various domains of asymmetric catalysis. ${ }^{2}$ There are several documented ways of providing scalemic BINOLs by kinetic resolutions, ${ }^{3,4}$ by enzymatic hydrolysis of BINOL-based esters, ${ }^{5}$ and by enantiomeric separation on chiral stationary phases. ${ }^{6}$ Good enantiomeric purity of BINOLs has been

\footnotetext{
$\dagger$ National Taiwan Normal University.
}

$\doteqdot$ National Taiwan University.

(1) For recent reviews, see: (a) Kagan, H. B.; Riant, O. Chem. Rev. 1992, 92, 1007. (b) Mikami, K.; Shimizu, M. Chem. Rev. 1992, 92, 1021. (c) Pu, L. Chem. Rev. 1998, 98, 2405. (d) Noyori, R. Asymmetric Catalysis in Organic Synthesis; Wiley and Sons: New York, 1994. For leading references, see: (e) Kobayashi, S.; Komiyama, S.; Ishitani, H. Angew. Chem., Int. Ed. 1998, 37, 979. (f) Ishihara, K.; Nakamura, H.; Yamamoto, H. J. Am. Chem. Soc. 1999, 121, 7720.

(2) (a) Noyori, R. Chem. Soc. Rev. 1989, 18, 187. (b) Noyori, R.; Takaya, H. Acc. Chem. Res. 1990, 23, 345.

(3) (a) Feringa, B.; Wynberg, H. Bioorg. Chem. 1978, 7, 397. (b) Kawashima, M.; Hirata, R. Bull. Chem. Soc. Jpn. 1993, 66, 2002.

(4) Toda, F.; Tanaka, K. J. Org. Chem. 1988, 53, 3607. achieved in several instances. However, the stoichiometric use of these resolving agents as well as a rather limited substrate scope of BINOLs examined still hinder their practical applications. Efforts toward asymmetric synthesis of BINOLs have received preliminary success by utilizing coupling methods mediated by $\mathrm{CuCl}_{2}$ in the presence of optically active amines, ${ }^{7}$ by electrocatalysis in the presence of stoichiometric sparteine, ${ }^{8}$ or by $\mathrm{Co}(\mathrm{acac})_{3}$ with chiral $\mathrm{Ru}(\mathrm{II})$ complexes as photosensitizers. ${ }^{9}$ However, a catalytic version of this process was not extensively explored. So far,

(5) Miyano, S.; Kawahara, K.; Inoue, Y.; Hashimoto, H. Tetrahedron Lett. 1987, 355 .

(6) Pirkle, W. H.; Schreiner, J. L. J. Org. Chem. 1981, 46, 4988

(7) (a) Smrčina, M.; Lorenc, M.; Hanuš, V.; Sedmera, P.; Kočovský, P. J. Org. Chem. 1992, 57, 1917. (b) Smrčina, M.; Poláková, J.; Vyskočil, S . Kočovský, P. J. Org. Chem. 1993, 58, 4534. (c) Smrčina, M.; Vyskočil, S.; Mača, B.; Polášek, M.; Claxton, T. A.; Abbott, A. P.; Kočovský, P. J. Org. Chem. 1994, 59, 2156. (d) Brussee, J.; Groenendijk, J. L. G.; te Kopple, J. M.; Jansen, A. C. A. Tetrahedron 1985, 16, 3313.

(8) Osa, T.; Kashiwagi, Y.; Yanagisawa, Y.; Bobbitt, J. M. J. Chem. Soc., Chem. Commun. 1994, 2535.

(9) (a) Hamada, T.; Ishida, H.; Usui, S.; Watanabe, Y.; Tsumura, K.; Ohkubo, K. J. Chem. Soc., Chem. Commun. 1993, 909. (b) During the submission of our manuscript for publication, a catalytic version of this process was recently realized by chiral (NO)Ru(II)- salen complexes..$^{9 \mathrm{c}}$ (c) Irie, R.; Masutani, K.; Katsuki, T. Synlett 2000, 1433. 
the most successful system involves the use of a $\mathrm{CuCl}-$ chiral diamine based catalyst for aerobic oxidative couplings of 3-carboalkoxy-2-naphthols. ${ }^{10}$

Oxovanadium(IV) complexes have been commonly utilized as precatalysts for olefin epoxidation and sulfide oxidation when combined with $\mathrm{O}_{2}$ or peroxide co-oxidants. ${ }^{11}$ By taking advantage of their electrophilic nature toward oxygen functionality, ${ }^{12}$ we have recently unraveled the catalytic activity of 2,2'-biphenol-based vanadyl complexes toward Mukaiyama aldol additions. ${ }^{13}$ A diastereoselectivity of up to $90 / 10$ (anti/syn) was achieved in the preliminary study. As part of our continuing search for asymmetric variants of oxovanadium(IV) complexes along with the recent finding of Uang on the use of $\mathrm{V}(\mathrm{O})(\mathrm{acac})_{2}$ in the aerobic oxidative coupling of 2-naphthols, ${ }^{14}$ we focussed on developing a new type of tridentate chiral vanadyl complex specifically active for both the aldol and the coupling processes. We herein describe our preliminary findings for the first successful application of these compounds in catalytic asymmetric oxidative couplings of various 2-naphthol derivatives.

Preliminary searches of chiral vanadyl complexes from a wide variety of chiral templates were futile in terms of their reactivity and turnover efficiency. These include BINAP, ${ }^{2}$ Evan's and Nishiyama's bis-oxazolines, ${ }^{15} \mathrm{O}$-acetyl mandelic acid, $N$-tosyl $\alpha$-amino acids, ${ }^{16}$ and several tridentate (Bolm's ${ }^{11 c}$ ) or tetradentate (Jacobsen's ${ }^{17}$ ) Schiff bases. We have subsequently discovered that tridentate Schiff bases derived from functionalized salicylaldehydes and $\alpha$-amino acids exhibit unique catalytic attributes toward aerobic oxidative couplings of 2-naphthol when combined with suitable vanadyl salts. ${ }^{18}$ Mass analyses of these complexes by the FAB technique suggest that they are mainly composed of tetradentate monomers and pentddentate dimers. ${ }^{19}$

Seven different salicylaldehydes with varying steric and/ or electronic demands at the $\mathrm{C} 3 \mathrm{and} /$ or $\mathrm{C} 5$ positions and two hydroxy-substituted naphthaldehydes were examined to gain insights into their stereoelectronic influences on the reactivity and enantioselectivity of the coupling process, Figure 1. Valine was chosen as the test $\alpha$-amino acid for the complex

(10) (a) Nakajima, M.; Miyoshi, I.; Kanayama, K.; Hashimoto, S.-I.; Noji, M.; Koga, K. J. Org. Chem. 1999, 64, 2264 and references therein. (b) A catalytic cross-coupling protocol with a $\mathrm{CuCl}_{2}-$ sparteine $-\mathrm{AgCl}$ based system was first demonstrated by Smrčina and Kočovský (ref 7b).

(11) (a) Nakajima, K.; Kojimo, M.; Fujita, J. Chem. Lett. 1986, 1483. (b) Takai, T.; Yamada, T.; Mukaiyama, T. Chem. Lett. 1990, 1657. (c) Bolm, C.; Bienewald, F. Angew. Chem., Int. Ed. Engl. 1995, 34, 2640.

(12) (a) Dichmann, K.; Hamer, G.; Nyburg, S. C.; Reynold, S. W. F. J. Chem. Soc. D 1970, 1295. (b) For DMSO complexes, see: Agarwal, K.; Singh, G. J. Indian Chem. Soc. 1986, 63, 926.

(13) Chen, C.-T.; Hon, S.-W.; Weng, S.-S. Synlett 1999, 816.

(14) Hwang, D. R.; Chen, C. P.; Uang, B. J. J. Chem. Soc., Chem. Commun. 1999, 1207.

(15) (a) Evans, D. A.; Burgey, C. S.; Kozlowski, M. C.; Tregay, S. W. J. Am. Chem. Soc. 1999, 121, 686 and references therein. (b) Nishiyama, H.; Kondo, M.; Nakamura, T.; Itoh, K. Organometallics 1991, 10, 500.

(16) (a) Kiyooka, S.-I.; Kaneko, Y.; Komura, M.; Matsuo, H.; Nakano, M. J. Org. Chem. 1991, 56, 2276. (b) Parmee, E. R.; Tempkin, O.; Masamune, S. J. Am. Chem. Soc. 1991, 113, 9365. (c) Corey, E. J.; Cywin, C. L.; Roper, T. D. Tetrahedron Lett. 1992, 33, 6907.

(17) (a) Annis, D. A.; Jacobsen, E. N. J. Am. Chem. Soc. 1999, 121, 4147. (b) Zhang, W.; Jacobsen, E. N. J. Org. Chem. 1991, 56, 2296.

(18) Theriot, L. J.; Carlisle, G. O.; Hu, H. J. J. Inorg. Nul. Chem. 1969, 31. 2841.

(19) See the Supporting Information.

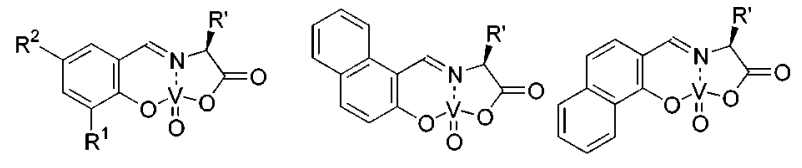

1: $\mathbf{R}^{1}=\mathrm{R}^{2}=t-B u \quad 5: R^{1}=H, R^{2}=t-B u \quad 8$

2: $R^{1}=t-B u, R^{2}=O M e \quad 6: R^{1}=B r, R^{2}=t-B u$

3: $\mathrm{R}^{1}=t-\mathrm{Bu}, \mathrm{R}^{2}=\mathrm{NO}_{2} \quad$ 7: $\mathrm{R}^{1}=\mathrm{R}^{2}=\mathrm{Br}$

4: $\mathrm{R}^{1}=\mathrm{adm}, \mathrm{R}^{2}=\mathrm{Me}$

Figure 1. Nine different vanadyl complexes derived from salicylaldehydes or hydroxynaphthaldehydes and $\alpha$-amino acids

formation in view of its greater chance to induce the highest level of asymmetric control under various conditions. ${ }^{20}$

The coupling reaction of 2-naphthol catalyzed by $10 \mathrm{~mol}$ $\%$ of vanadyl complexes 1-9 was selected as a test system. The model reactions were all carried out in $\mathrm{CCl}_{4}$ at ambient temperature under an oxygen atmosphere, and the results are compiled in Table $1 .{ }^{21}$ For all catalysts except $\mathbf{6 d}$ (entry 6),

Table 1. Effects of Catalyst Templates on the Catalytic Asymmetric Couplings of 2-Naphthol

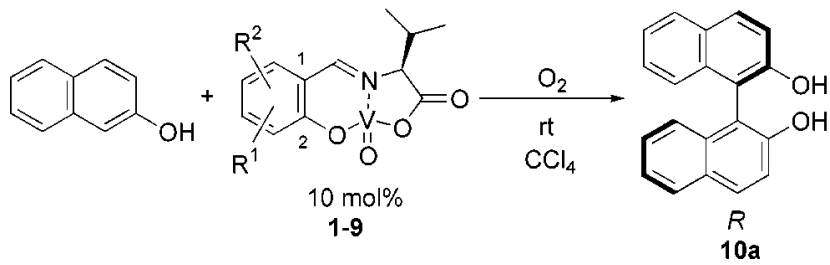

\begin{tabular}{ccccc}
\hline entry & catalyst & time (days) & yield, \% & ee, \%a \\
\hline 1 & 1d & 3 & 94 & 25 \\
2 & 2d & 3 & 83 & 31 \\
3 & 3d & 12 & 78 & 22 \\
4 & 4d & 12 & 78 & 22 \\
5 & 5d & 10 & 92 & 30 \\
6 & 6d & 7 & 42 & 5 \\
7 & 7d & 8 & 100 & 26 \\
8 & 8d & 6 & 94 & 62 \\
9 & 9d & 7 & 86 & 42
\end{tabular}

${ }^{a}$ Determined by HPLC analysis on a Chiralcel AD column.

the coupling reactions went to completion in 3-12 days, providing scalemic $(R)$-BINOL in $74-100 \%$ yields. ${ }^{19}$ For the 3-tert-butyl-substituted catalysts $\mathbf{1 d}-\mathbf{3 d}$, appending an electron-withdrawing substituent at $\mathrm{C} 5$ (e.g., $\mathrm{R}^{2}=\mathrm{NO}_{2}$ ) reduces both coupling efficiency and enantioselectivity (compare entries 1-3). For the 5-methyl- and 5-tert-butylsubstituted catalysts $\mathbf{1 d}, \mathbf{4 d}$, and $\mathbf{5 d}$, increasing the steric bulk at $\mathrm{C} 3$ (e.g., $\mathrm{R}^{1}=$ adamantyl) slows down the coupling

(20) Cogan, D. A.; Liu, G.; Kim, K.; Backes, B. J.; Ellman, J. A. J. Am. Chem. Soc. 1998, 120, 8011.

(21) Among the six different solvent classes (chloroalkanes, ethers, nitroalkanes, nitriles, alcohols, and arenes) examined, the best asymmetric inductions were observed for coupling reactions conducted in $\mathrm{CCl}_{4}$. 
reaction with slightly diminished enantioselectivity (compare entries 1 and 4). Among them, the better result (30\% $\left.\mathrm{ee}^{22}\right)$ was observed in the coupling reaction catalyzed by $\mathbf{5 d}$ where no substituent $\left(\mathrm{R}^{1}=\mathrm{H}\right)$ was incorporated at $\mathrm{C} 3$ (entry 5).

A similar trend was observed in the hydroxy-naphthaldehyde based system. Better coupling enantiocontrol (62\% ee, entry 8) was achieved with catalyst 8d (a 5,6-benzosalicylaldehyde) than with 9d (a 3,4-benzosalicylaldehyde). To our knowledge, catalyst $8 \boldsymbol{d}$ represents one of the best systems for the catalytic asymmetric coupling of 2-naphthol. ${ }^{9 \mathrm{~b}, \mathrm{c}}$ In addition, the enantiomeric purity of the resultant scalemic BINOL (62\% ee) can easily be upgraded to $100 \%$ by simple recrystallization. ${ }^{23}$

We have further investigated the catalytic profiles of $\mathbf{8} \mathbf{a}-$ $\mathbf{i}$, bearing six different natural and three unnatural $\alpha$-amino acids, in the model reaction. Better asymmetric inductions and chemical yields were achieved in catalytic systems derived from phenylalanine (8a, 44\% ee), valine (8d, $62 \%$ ee), and tert-leucine (8g, $57 \%$ ee), Table 2.

Table 2. Effects of Amino Acids in $\mathbf{8}$ on the Catalytic Asymmetric Coupling of 2-Naphthol in $\mathrm{CCl}_{4}$<smiles>[R]C1C(=O)O[V](O)(O)N1C=Cc1c(O)ccc2ccccc12</smiles>

8a-h

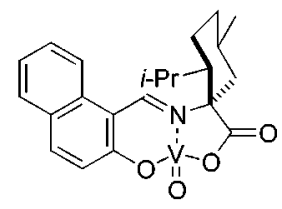

$\mathbf{8 i}$

\begin{tabular}{cllc}
\hline catalyst & \multicolumn{1}{c}{$\mathrm{R}^{\prime}$} & yield, \% & $\mathrm{ee}, \%$ \\
\hline $\mathbf{8 a}$ & $\mathrm{PhCH}_{2}$ & 82 & 44 \\
$\mathbf{8 b}$ & indole-CH & \\
$\mathbf{8 c}$ & imid-CH & 38 & 45 \\
$\mathbf{8 d}$ & $\mathrm{i}-\mathrm{Pr}$ & trace & 0 \\
$\mathbf{8 e}$ & $\mathrm{sec}-\mathrm{Bu}$ & 94 & 62 \\
$\mathbf{8 f}$ & $\mathrm{i}-\mathrm{Bu}$ & 84 & 33 \\
$\mathbf{8 g}$ & $\mathrm{t}-\mathrm{Bu}$ & 95 & 22 \\
$\mathbf{8 h}$ & $\mathrm{Ph}$ & 98 & 57 \\
$\mathbf{8 i}$ & (-)-menthyl & 38 & 16 \\
& & 90 & 10
\end{tabular}

Tryptophan-based catalyst $(\mathbf{8 b}, 38 \%)$ provided the coupling product $(R)$-10a with significantly lower yield than that mediated by phenylalanine-based $\mathbf{8 a}(82 \%)$. The complex derived from histidine (8c) was found to be catalytically inactive presumably due to the extra coordination by the imidazole ring in 8c. The complex prepared from (-)menthone-derived $\alpha$-amino acid can smoothly effect the aerobic oxidative coupling of 2-naphthol but with a very poor ee $(10 \%)$.

With the optimal phenylalanine-, valine-, and tert-lucinebased catalysts (8a, 8d, and $\mathbf{8 g}$ ) in hand, we further explored substrate scopes with varying substitution at C3, C6, or C7

(22) Defined as $(\% R-\% S / \% R+\% S) \times 100$.

(23) In almost all instances, the crystals crashed out in racemic form. Nevertheless, the solids collected after concentration of the mother liquors turned out to be enantiomerically pure. of 2-naphthols. In all cases, either $\mathbf{8 a}$ or $\mathbf{8 d}$ led to the best coupling results, Table 3 . For the seven different 2-naphthols

Table 3. Effects of Substrates on the Catalytic Asymmetric Couplings Mediated by $\mathbf{8 a}$ and $\mathbf{8 d}$<smiles></smiles>

(R)-10a: $\mathrm{R}^{2}=\mathrm{R}^{3}=\mathrm{H}$ (R)-10b: $\mathrm{R}^{2}=\mathrm{Br}, \mathrm{R}^{3}=\mathrm{H}$ $(R)-10 \mathrm{c}: \mathrm{R}^{2}=\mathrm{OMe}, \mathrm{R}^{3}=\mathrm{H}$ $(R)$-10d: $\mathrm{R}^{2}=\mathrm{H}, \mathrm{R}^{3}=\mathrm{OMe}$<smiles>[R]c1cc2ccccc2c(-c2c(O)c([R])cc3ccccc23)c1O</smiles>

(S)-10f: $R^{1}=O B n$ $(R)$-10g: $\mathrm{R}^{1}=\mathrm{CPh}_{2}(\mathrm{OH})$
(S)-10e: $R^{1}=$ OMe

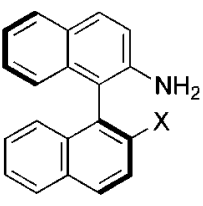

(S)-11a: $X=\mathrm{OH}$ (S)-11b: $X=\mathrm{NH} 2$

\begin{tabular}{|c|c|c|c|c|}
\hline catalyst $^{a}$ & time, days & product & yield, \% & ee, $\% \mathrm{~b}, \mathrm{c}$ \\
\hline 8d & 9 & $10 a$ & $94\left(72^{d}\right)$ & $62(65)$ \\
\hline $8 d^{\prime}$ & 4.5 & $10 a$ & 92 & 59 \\
\hline $8 d$ & 7 & $10 b$ & $97(82)$ & $52(68)$ \\
\hline $8 d^{\prime}$ & 2 & $10 b$ & 95 & 51 \\
\hline $8 a^{e}$ & 3 & $10 c$ & 100 & 39 \\
\hline $8 a$ & 6 & 10d & 86 & 58 \\
\hline $\mathbf{8} \mathbf{d}^{f}$ & 15 & $10 e$ & 75 (73) & $-56^{9}(33)$ \\
\hline $8 d$ & 8 & $10 f$ & 91 (95) & $-689(24)$ \\
\hline $8 a$ & 15 & $10 \mathrm{~g}$ & 98 & $35^{9}$ \\
\hline $8 \mathbf{d}^{\mathrm{h}}$ & 11 & $11 a$ & $74(42)$ & $-33(46)$ \\
\hline $8 d^{e}$ & 11 & $11 b$ & 48 & -10 \\
\hline
\end{tabular}

${ }^{a} \mathrm{CCl}_{4}$ was used as reaction solvent unless otherwise stated. ${ }^{b}$ Determined by HPLC analysis on Chiralpak AD or AS or Chiralcel OD column. ${ }^{c}$ Defined as $(\% R-\% S / \% R+\% S) \times 100 .{ }^{d}$ The data in parentheses correspond to the most selective results reported in refs $7 \mathrm{~b}, 9 \mathrm{c}$, and 10 . ${ }^{e}$ Reaction was carried out in $\mathrm{CH}_{2} \mathrm{Cl}_{2} .{ }^{f}$ Reaction was carried out in toluene. ${ }^{g}$ Configuration determined by the exciton chirality observed in CD spectra. ${ }^{h}$ Reaction was carried out in anisole.

examined, the resultant coupling products $\mathbf{1 0 a}-\mathbf{g}$ were prepared in $75-100 \%$ yields and with ees in the range 35$68 \%$. Better asymmetric inductions were observed in the parent BINOL 10a (62\% ee), 6,6'-dibromo-BINOL 10b (52\% ee), 7,7'-dimethoxy-BINOL 10d (58\% ee), 3,3'-dimethoxyBINOL 10e $(-56 \%$ ee), and 3,3'-dibenzoxy-BINOL 10e ( $-68 \%$ ee). Appending an electron-donating substituent at the C6 of 2-naphthol $\left(\mathrm{R}^{2}=\mathrm{OMe}\right)$ led to 10c with an ee diminished by $23 \%$. It should be noted that attaching an alkoxy substituent at $\mathrm{C} 3$ of 2-naphthol $\left(\mathrm{R}^{1}=\mathrm{OMe}, \mathrm{OBn}\right)$ resulted in complete reversal of enantioselectivities. On the other hand, increasing the steric bulk at this position $\left(\mathrm{R}^{1}=\right.$ $\mathrm{CPh}_{2}(\mathrm{OH})$ ) resulted in eroded enantiocontrols in the coupling process (35\% ee). Substitutions with carbomethoxy and hydroxymethyl at $\mathrm{C} 3$ completely suppress the coupling reactivity.

The catalytic protocol is also amenable to the coupling of 2-aminonaphthalene, albeit with poorer chemical yield (48\%) and ee $(-10 \%)$. Cross coupling between 2-naphthol and 2-aminonaphthalene ${ }^{24}$ was found to be feasible, furnishing 11a in $74 \%$ yield and $-33 \%$ ee. The enantiocontrol is somewhat comparable to the only documented example by a diastereoselective crystallization of a $\mathrm{Cu}$ (II)-amine-product 
process. $^{7 \mathrm{~b}}$ More importantly, this particular case represents the first successful example of accessing scalemic 11a by catalytic asymmetric coupling methodology. The latter two products (11a and 11b) have been successfully utilized as chiral auxiliaries in asymmetric catalysis. ${ }^{25}$

To gain insights into the structure-reactivity relationship of our catalytic systems, single crystals suitable for X-ray analysis were obtained by recrystallization of $\mathbf{8 d}$ from $\mathrm{MeOH}$. The X-ray structure shows that it has been oxidized to a distorted octahedral $\mathrm{V}^{\mathrm{V}}$ species $\left(\mathbf{8 d}^{\prime}\right)$ with two extra coordinating ligands from $\mathrm{MeOH}$ (Figure 2). ${ }^{26}$ One methanol

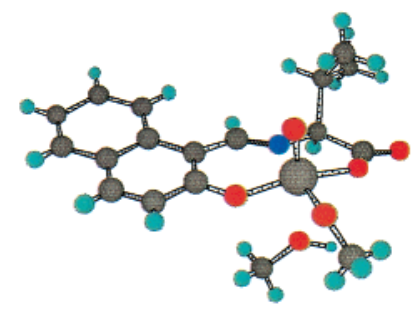

Figure 2. Chem-3D presentation for the X-ray structure of $\mathbf{8} \mathbf{d}^{\prime}$.

is positioned anti to the $\mathrm{V}=\mathrm{O}$. The other is covalently linked and is anti to the imine nitrogen. In addition, the $\mathrm{V}=\mathrm{O}$ bond is syn to the isopropyl group in the chiral template. Since the couplings can also be smoothly carried out by catalyst $\mathbf{8 d}$ ' with reaction rates enhanced at least 2 times (entries 2 and 4), $\mathrm{V}^{\mathrm{IV}}$ complex $\mathbf{8 d}$ apparently serves as a precatalyst.
In addition, we suggest that a monomeric $\mathrm{V}^{\mathrm{V}}$ complex such as $\mathbf{8} \mathbf{d}^{\prime}$ but not a dimeric $\mathrm{V}^{\mathrm{V}}-\mathrm{O}-\mathrm{V}^{\mathrm{V}}$ complex function as the active catalyst, as supported by the observed linear ee dependence of $(R)$-BINOL on the ee of complex $\mathbf{8 d} .{ }^{19}$

In conclusion, we have documented the first successful catalytic asymmetric couplings of various 2-naphthols mediated by chiral tridentate vanadyl complexes derived from salicylaldehydes and $\alpha$-amino acids. To our knowledge, our catalytic system represents one of the most enantioselective catalytic couplings mediated by chiral metal complexes.

Acknowledgment. We are grateful to the National Science Council of the Republic of China for a generous support of this research.

Supporting Information Available: The optimal procedures for the preparation of catalyst $\mathbf{8 a}$ and for its mediated coupling of 2-naphthol, full spectroscopic characterizations of $\mathbf{1 0 a}-\mathbf{g}, \mathbf{1 1 a}$, and 11b, and the linear plot. This material is available free of charge via the Internet at http://pubs.acs.org.

OL015505O

(24) A preformed hydrogen-bonded 1:1 complex was used as the coupling substrate, see: Ding, K.; Xu, Q.; Wang, Y.; Liu, J.; Yu, Z.; Du, B.; Wu, Y.; Koshima, H.; Matsuura, T. J. Chem. Soc., Chem. Commun. 1997, 693.

(25) (a) Carreira, E. M.; Singer, R. A.; Lee, W. J. Am. Chem. Soc. 1994 116, 8837. (b) Zhou, X. G.; Yu, X. Q.; Huang, J. S.; Li, S. G.; Li, L. S.; Che, C. M. J. Chem. Soc., Chem. Commun. 1999, 1789. (c) Vyskočil, S.; Jaracz, S.; Smrčina, M.; Stícha, M.; Hanuš, V.; Polášek, M.; Kočovský, P. J. Org. Chem. 1998, 63, 7727.

(26) (a) For the related X-ray structure of a $\mathrm{V}^{\mathrm{V}}$ complex from salicylaldehyde and L-alanine, see: Nakajima, K.; Kojima, M.; Toriumi, K.; Saito, K.; Fujita, J. Bull. Chem. Soc. Jpn. 1989, 62, 760. (b) See also: Nitta, H.; Yu, D.; Kudo, M.; Mori, A.; Inoue, S. J. Am. Chem. Soc. 1992, 114, 7969. 